\title{
Systemic lupus erythematosus with hypothyroidism as the initial clinical manifestation: A case report
}

\author{
XUEJIAO ZHANG ${ }^{1 *}$, BAOFENG XU ${ }^{2 *}$, ZIWEI LIU ${ }^{1}$, YUANYUAN GAO $^{1}$, QING WANG $^{1}$ and RUI LIU ${ }^{3}$ \\ ${ }^{1}$ Department of Endocrinology, China-Japan Union Hospital of Jilin University, Changchun, Jilin 130033; \\ ${ }^{2}$ Department of Neurosurgery, The First Hospital of Jilin University, Changchun, Jilin 130021; \\ ${ }^{3}$ Department of VIP Unit, China-Japan Union Hospital of Jilin University, Changchun, Jilin 130033, P.R. China
}

Received September 25, 2019; Accepted February 4, 2020

DOI: $10.3892 / \mathrm{etm} .2020 .8788$

\begin{abstract}
Systemic lupus erythematosus (SLE) is a multisystem autoimmune disease and hypothyroidism is an organ-specific autoimmune disease. The two diseases may occur successively or simultaneously. The majority of previous studies observed that thyroid disease was more frequent in patients with SLE than in the general population, particularly those who had a higher incidence of anti-thyroid antibodies. However, there are no reported cases of SLE with hypothyroidism as the initial clinical manifestation, to the best of our knowledge. The present study reported on a case of SLE with this unusual initial clinical manifestation and reviewed the literature to estimate the prevalence of clinical hypothyroidism in patients with SLE (range, 3.0-21.4\%). The case of the present study had no obvious facial erythema, photosensitivity or recurrent oral ulcers, and only had hypothyroidism as the initial clinical symptom, but the laboratory examination supported the diagnosis of SLE. The present study suggested that in the clinical diagnosis, attention should be paid to screening for connective tissue diseases when diagnosing hypothyroidism, and the importance of thyroid dysfunction should also be recognized in the treatment of SLE.
\end{abstract}

\section{Introduction}

Systemic lupus erythematosus (SLE) is a multisystem autoimmune disease of the connective tissue characterized by

Correspondence to: Dr Qing Wang,Department of Endocrinology, China-Japan Union Hospital of Jilin University, 126 Xiantai Street, Changchun, Jilin 130033, P.R. China

E-mail:wq@jlu.edu.cn

Dr Rui Liu, Department of VIP unit, China-Japan Union Hospital of Jilin University, Changchun, Jilin 130033, P.R.China

E-mail: liur@jlu.edu.cn

*Contributed equally

Key words: systemic lupus erythematosus, hypothyroidism, initial clinical, prevalence, autoantibodies, pericardial effusion heterogeneous manifestations, production of autoantibodies (AAbs) and chronic inflammation of numerous organs, with a higher prevalence among females (1). The pathogenesis includes local deposition of anti-nuclear antibodies (ANA) and activation of the complement system (2). Although the prognosis of patients with SLE has improved in the past decade as a result of improvements in diagnosis and medical technology, the mortality rates in patients with lupus remain 2-5 times higher than in the general population (3). Autoimmune diseases may be divided into organ-specific and systemic autoimmune diseases. The former most frequently affect the thyroid gland, characterized by destruction of thyroid follicular cells and leading to hypothyroidism. The latter mainly refer to connective tissue diseases, including rheumatoid arthritis, SLE, myositis and systemic sclerosis $(4,5)$. Hypothyroidism and SLE are autoimmune diseases and may occur together, but usually have their own characteristic clinical manifestations. The present study reported on a case of SLE with hypothyroidism as the initial clinical manifestation and the literature was reviewed.

Case report. A 31-year-old female with a history of face and bilateral leg swelling without any obvious inducement over the preceding 6 months, accompanied by lethargy, memory loss, lack of concentration, shortness of breath and wheezing, presented to the department of Endocrinology, China-Japan Union Hospital of Jilin University, Changchun, Jilin in May 2019. As the symptoms did not significantly impact the patient's daily life, no systematic diagnosis or treatment were determined. However, 5 and a half months after the patient first presented, these symptoms worsened and were accompanied by dyspnea, at which point the patient was examined at the outpatient department of China-Japan Union Hospital of Jilin University (Changchun, China). Assessment of thyroid function provided the following values: Thyroid-stimulating hormone, $100.00 \mathrm{mUI} / \mathrm{l}$; free triiodothyronine, $0.78 \mathrm{pmol} / \mathrm{l}$; and free thyroxine, $1.3 \mathrm{pmol} / \mathrm{l}$ (Table I). Cardiac ultrasonography revealed massive pericardial effusion. During the course of the disease, there was no facial erythema, photosensitivity, recurring oral ulcers; when the patient first presented they were occasional morning stiffness, hair loss or myalgia, which was apparent in the proximal extremities of the bilateral legs. Physical examination revealed the following: 
Body temperature, $36.5^{\circ} \mathrm{C}$; blood pressure, $112 / 70 \mathrm{mmHg}$; pulse, 72 beats/min; respiration, 16 times $/ \mathrm{min}$. The patient did not have any rash; however, the patient presented with slow response, apathy, dry skin, edema of eyelids and face and hypertrophy of lips; the enlargement of thyroid is in the stage of first degree, thyroid texture is tough, no tenderness, and no murmur on auscultation of thyroid. The patient's heart rhythm was uniform, the sound of the heart was distant, low and dull, and no murmur was heard on auscultation of heart. The patient exhibited severe non-concave edema of the bilateral lower limbs, normal muscle tension of limbs, muscle strength at level 5, weakened bilateral knee reflex and ankle reflex, and no joint swelling or motion disorder. The patient's body weight was $80 \mathrm{~kg}$. Relevant examinations were completed on admission and results are listed in Table I. Immunoglobulin and complement were normal. A microadenoma was identified by pituitary nuclear magnetic resonance imaging (Fig. 1A and B). A chest CT scan revealed pericardial effusion (Fig. 1C). Cardiac ultrasonography revealed massive pericardial effusion. A right deltoid muscle biopsy was performed and indicated that the majority of the muscle fiber tissues were atrophied and degenerated, and lymphocytes were occasionally observed among the muscle fibers (Fig. 2A). Myositis was not excluded based on morphology. Lymphocyte immunohistochemistry was as follows: Lymphocytes were negative for CD4 and CD8 (Fig. 2B and C). The patient was treated with initiated thyroid hormone replacement therapy with oral levothyroxine ( $25 \mu \mathrm{g}$ /day). Pericardiocentesis was performed under CT guidance, and $\sim 1,000 \mathrm{ml}$ of pericardial fluid was removed via an anterior approach with placement of a catheter. The characteristics of the pericardial fluid were as follows: The rivalta experiment was positive, which is a qualitative determination test of serous mucin used to distinguish the exudate from the leaking fluid and the result of the exudate should be positive (6); leucocyte count, $7.1 \times 10^{7} / 1$; glucose, $5.0 \mathrm{mmol} / 1$; protein, $58.2 \mathrm{~g} / \mathrm{l}$; chloride, $106.8 \mathrm{mmol} / \mathrm{l}$; mononuclear leucocytes, $82 \%$; polynuclear leucocytes, $18 \%$; adenosine deaminase, $11.7 \mathrm{U} / \mathrm{l}$; and lactate dehydrogenase, $466.19 \mathrm{IU} / 1$. After pericardiocentesis, the dyspnea symptoms gradually alleviated. The dose of thyroxine was gradually adjusted during hospitalization. After 18 days, the patient was discharged on oral thyroxine $(87.5 \mu \mathrm{g} /$ day $)$. The patient was followed up at the outpatient clinic 3 weeks and 3 months after being discharged (Table I).

\section{Discussion}

A systematic literature search of the PubMed and CNKI databases was performed to identify studies published from 1987 to the present day containing information on the prevalence of hypothyroidism in SLE patients (Table II). The majority of the studies identified reported a high incidence of hypothyroidism in patients with SLE; the prevalence of clinical hypothyroidism reported in the literature ranged from 3.0 to $21.4 \%$ (7-25). The prevalence was higher in females compared with that in males, with the incidence rate estimated to be 9 -fold higher in females (26). Hypothyroidism in patients with SLE was associated with the presence of abnormal AAbs, hypoechoic pattern of the thyroid and small thyroid volume, suggesting that autoimmunity has an important role in the pathogenesis of hypothyroidism in SLE (9). Studies have indicated that arthritis and skin damage are more common in patients with SLE with hypothyroidism, while fewer neuropsychiatric symptoms and hematological abnormalities were observed (15). The association between SLE and thyroid dysfunction has been established since 1961 (27). Most of the previous studies reported a higher prevalence of SLE in patients with hypothyroidism (4-26). However, there were no reported cases of SLE with the only or the initial symptom of hypothyroidism, the present study reported on a case to highlight the diversity of the disease. SLE is a multifactorial autoimmune disease with a complex pathogenesis and clinical manifestations (28). The present case and previous studies suggest that hypothyroidism is more likely to occur in patients with SLE in whom there is a higher incidence of anti-thyroid antibodies (7-26); the reason for this remains elusive. The pathogenesis of hypothyroidism in patients with SLE may be due to the following factors: i) Autoimmunity has an important role in hypothyroidism associated with SLE (29). Systemic and organ-specific autoimmune diseases are associated with each other. SLE is a prototype of autoimmune diseases characterized by its multi-organ involvement. Previous reports indicated that the presence of positivity for anti-thyroglobulin antibodies (A-TG) and anti-thyroid peroxidase antibodies (TPOAb) in patients with SLE were significantly higher than those in the control group of healthy individuals (8-24). Patients with SLE have a variety of AAbs, including anti-Smith (anti-Sm) and anti-nucleosome antibodies (30), which tend to cause autoimmune inflammation. Lymphocytic infiltration of the thyroid gland destroys thyroid follicles and induces apoptosis of thyroid tissue cells, and A-TG and TPOAb may result from polyclonal B-cell activation (31). ii) An early animal study indicated that the incidence of autoimmune thyroid diseases in a murine lupus model, MRL-lpr/lpr mice, was significantly increased, suggesting that the two diseases may have similar immune deficiency or immune regulatory mechanisms (32). Later studies suggested that two human leukocyte antigens (HLA), HLA-DRW3 and HLA-B8, and the interactions among autoimmune cytokines have important roles in the occurrence of hypothyroidism in SLE (5,33-37). The two HLAs are highly expressed in patients with SLE and hypothyroidism and may promote the formation of AAbs. These two autoimmune diseases are mediated by $\mathrm{T}$ cells and B cells and the mechanism for autoimmune destruction probably involves cellular immunity and humoral immunity (38), causing lymphocytic infiltration of the thyroid gland by B cells and cytotoxic T cells; the function of T suppressor cells (Ts) is low, Thelper cells (Th) and B cells are hyperactive and the Ts/Th ratio decreases, causing the production of a large number of AAbs (39), and destruction of the thyroid gland. In addition, T cell-mediated antibodies inhibit the function of thyroid cells, leading to insufficient release of thyroxine, which causes hypothyroidism. iii) A previous study suggested that gene mutations have an important role in SLE with hypothyroidism (40). It examined the R620W polymorphism of the protein tyrosine phosphatase non-receptor type 22 gene, which encodes for a protein present on $\mathrm{T}$ cells, and discovered that individuals with this mutation were more likely than individuals without or with other gene mutations to develop concurrent SLE and hypothyroidism. iv) According to a study by Hijmans et al (27), organ-specific antigens are 
Table I. Vital signs and laboratory results at hospitalization and follow-ups.

\begin{tabular}{|c|c|c|c|c|}
\hline Parameter & Initial visit & Follow-up at 3 weeks & Follow-up at 3 months & Reference range \\
\hline Body weight (kg) & 80 & 73.5 & 71.8 & - \\
\hline Blood pressure (mmHg) & $106 / 63$ & $100 / 70$ & $110 / 80$ & - \\
\hline Heart rate (beats/min) & 78 & 75 & 86 & - \\
\hline TSH (mIU/l) & 100.00 & 30.79 & 11.32 & $0.37-4.94$ \\
\hline FT3 (pmol/l) & 0.40 & 4.42 & 4.68 & $3.10-6.80$ \\
\hline FT4 (pmol/l) & 0.90 & 11.30 & 9.20 & $12.00-22.00$ \\
\hline $\mathrm{Tg}(\mathrm{ng} / \mathrm{ml})$ & 14.21 & 9.65 & 0.04 & $0.10-23.00$ \\
\hline Anti-Tg (IU/l) & 297.80 & - & 313.80 & $0.00-35.00$ \\
\hline TPO (IU/l) & 160.40 & 130.50 & 131.70 & $0.00-34.00$ \\
\hline WBC $\left(\times 10^{9} / 1\right)$ & 3.17 & 5.76 & 4.98 & $4.00-10.00$ \\
\hline $\mathrm{HB}(\mathrm{g} / \mathrm{l})$ & 73.00 & 97.40 & 112.00 & $110.00-150.00$ \\
\hline PLT $\left(\times 10^{9} / 1\right)$ & 328.00 & 328.00 & 333.00 & $100.00-300.00$ \\
\hline Coomb's test & $(-)$ & $(-)$ & $(-)$ & $(-)$ \\
\hline $\mathrm{TG}(\mathrm{mmol} / \mathrm{l})$ & 2.09 & 1.89 & 1.00 & $<1.70$ \\
\hline $\mathrm{TC}(\mathrm{mmol} / \mathrm{l})$ & 6.91 & 4.26 & 4.35 & $3.00-5.70$ \\
\hline LDL-C (mmol/l) & 4.18 & 2.71 & 2.67 & $<4.13$ \\
\hline $\mathrm{ESR}(\mathrm{mm})$ & 18.00 & 30.00 & 12 & $0.00-5.00$ \\
\hline CRP (mg/l) & 6.26 & 13.43 & 9.86 & $0.00-5.00$ \\
\hline CK (IU/l) & 1339.76 & 149.71 & 93.00 & $26.00-140.00$ \\
\hline CK-MB (U/l) & 37.20 & 11.23 & 16.20 & $0.00-16.00$ \\
\hline LDH (U/l) & 1645.01 & 254.32 & 216.00 & $313.00-618.00$ \\
\hline PRL (mIU/l) & 1280.90 & - & 794.9 & $108.80-557.10$ \\
\hline ANA & $1: 100(+)$ & $1: 100(+)$ & $1: 100(+)$ & $(-)$ \\
\hline ANUA & $(+)$ & $(+)$ & $(+)$ & $(-)$ \\
\hline Anti-nRNP Antibodies & $(+)$ & $(-)$ & $(+)$ & $(-)$ \\
\hline Anti-Sm antibodies & $(+)$ & $(+)$ & $(+)$ & $(-)$ \\
\hline Pericardial effusion & $\begin{array}{c}\text { Deepest, } \\
37 \mathrm{~mm}\end{array}$ & Deepest, $13 \mathrm{~mm}$ & $(-)$ & $(-)$ \\
\hline
\end{tabular}

TSH, thyroid-stimulating hormone; FT3, free triiodothyronine; FT4, free thyroxine; Tg, thyroglobulin; Anti-Tg, anti-thyroglobulin antibody; TPO, thyroid peroxidase antibody; WBC, white blood cell; HB, hemoglobin; PLT, platelet; TG, triglyceride; TC, total cholesterol; LDL-C, low-density lipoprotein cholesterol; ESR, erythrocyte sedimentation rate; CRP, c-reactive protein; CK-MB, creatine kinase myocardial band; LDH, lactate dehydrogenase; PRL, prolactin; ANA, anti-nuclear antibodies; ANUA, anti-nucleosome antibodies; nRNP, anti-ribonucleoprotein; anti-Sm, anti-Smith antibodies.

able to evoke auto-antibody production. The auto-antibodies are mistakenly directed to attack healthy tissue. A degree of overlap of auto-antibodies appears to exist between SLE and thyroid autoimmune disease, either thyroid-specific antibodies or antibodies typical for systemic lupus. The prevalence of anti-TPO and A-TG is higher in SLE patients (4), but there is disagreement regarding which antibody is responsible for thyroid disease.

Hypothyroidism is an organ-specific autoimmune disease. It is a systemic hypometabolic syndrome caused by thyroid hormone deficiency or resistance due to various reasons, and its clinical manifestations include intolerance of cold, fatigue, lethargy, memory impairment, female menstrual disorders and infertility (41). Typical patients may have blank facial expressions, slow response, hoarse voice, hearing impairment, pale complexion, facial and/or eyelid edema, thick lips and enlarged tongue, frequently with tooth marks, dry and rough skin, peeling skin, decreased temperature, and sparse and dry hair. In a few cases, pretibial myxoedema occurs, and pericardial effusion and heart failure may occur when the heart is involved. In severe cases, myxoedema coma may occur (42).

SLE is a systemic non-specific autoimmune disease and clinical manifestations include weakness, fever, weight loss, photosensitivity, hair loss, oral ulcers, erythema, skin rash, joint pain, muscle aches and Raynaud's phenomenon. SLE may cause damage to numerous organs through the immune system, including the thyroid, joints, skin, blood vessels, heart, lungs, liver, kidney and nervous system $(25,43)$. Lupus and thyroid disorders may cause fatigue, focal edema, weakness, myalgias, arthralgias and a variety of other non-specific complaints. According to the classification and diagnostic criteria for SLE formulated by the American College of Rheumatology (ACR) in 2019 (44). The diagnostic criteria for SLE are positive ANA as an entry criterion, weighted criteria in seven clinical 

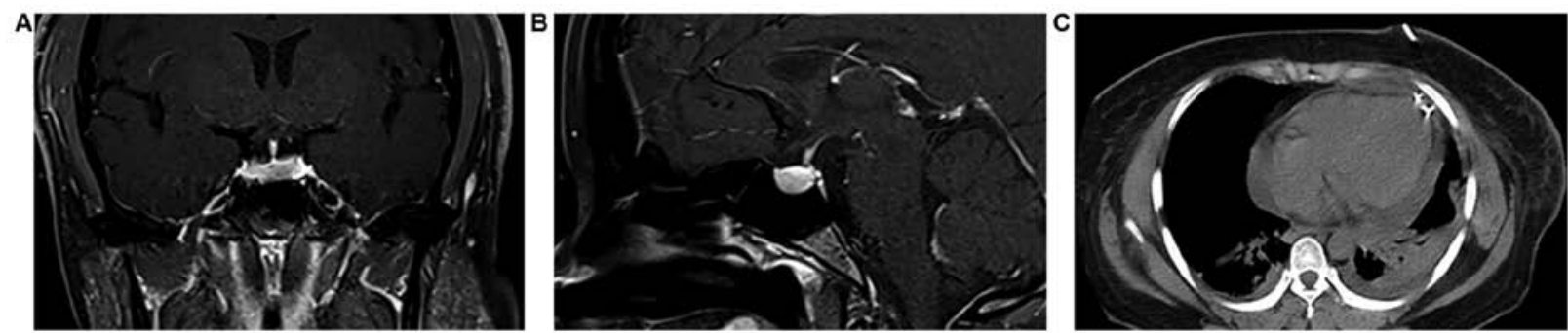

Figure 1. (A) Coronal view of the pituitary by MRI under T1 enhancement; a low signal may be observed at the left margin of the pituitary. (B) Sagittal view of the pituitary by MRI under T1 enhancement; low signal and slight distention are visible at the left margin of the pituitary; no obvious enlargement of the sella is observed, no obvious abnormalities are present in the optic chiasm and bilateral cavernous sinuses. (C) Chest CT scan revealing pericardial effusion; the pericardiocentesis drainage tube is visible; bilateral interlobar pleural thickening; pleural fluid is present on the left side of the chest.
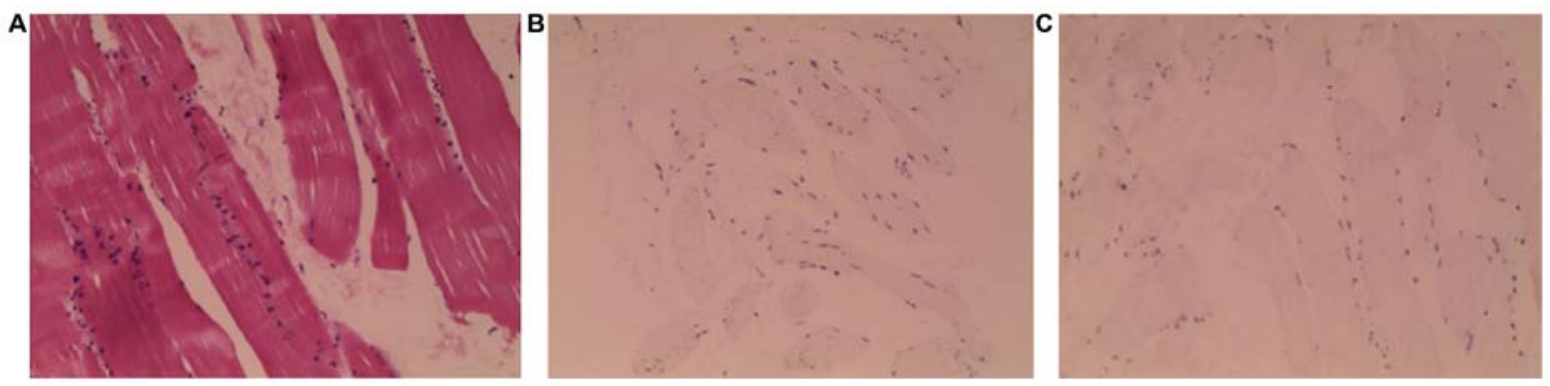

Figure 2. Histological staining of a muscle biopsy specimen. (A) On hematoxylin and eosin staining, lymphocytes scattered among the muscle fibers are visible; a small amount of striated muscle tissue is atrophic, denatured and nucleated (magnification, x100). (B) Immunohistochemical staining for lymphocyte marker CD4 is negative (magnification, $\mathrm{x} 100$ ). (C) Immunohistochemical staining for lymphocyte marker CD8 is negative (magnification, $\mathrm{x} 100$ ).

domains (constitutional, haematological, neuropsychiatric, mucocutaneous, serosal, musculoskeletal and renal) and three immunological domains [anti-phospholipid antibodies, low complements, anti-Sm and anti-double-stranded (ds)DNA as SLE-specific antibodies] and a classification threshold score of $\geq 10$. However, early clinical manifestations of SLE are atypical, and therefore, laboratory tests are necessary. The detection of autoantibodies has become an important and reliable basis for the diagnosis of SLE, as patients with SLE present with a variety of AAbs (45). A previous study revealed that positive detection of anti-nuclear antibodies has significance in the diagnosis of SLE (46). Among the 15 different IgG antibodies, anti-Sm, anti-dsDNA and anti-nucleosome antibodies are specific antibodies for SLE. Among them, the anti-Sm antibody occurs only in SLE, has high specificity and is considered to be a marker antibody for SLE. Anti-nucleosome antibodies appear in the early stage of SLE and contribute to the early diagnosis of SLE in combination with anti-nuclear antibodies. Anti-ribonucleoprotein (nRNP) antibodies may be expressed in a variety of autoimmune diseases without specificity (47). Zeng and Wu (48) analyzed AAbs in 150 patients with SLE and indicated that $5.33 \%$ of patients were positive for a single antibody, while the remaining $94.67 \%$ were positive for $\geq 2$ antibodies at the same time. The patient in the present case report had no obvious facial erythema, photosensitivity or recurrent oral ulcers, but did exhibit morning stiffness, hair loss and pericardial effusion, and laboratory results were positive for anti-nRNP and anti-Sm antibodies accompanied by changes in blood images. These symptoms were consistent with positive ANA as an entry criterion, leucopenia (white blood cell count $\left.<4.0 \times 10^{9} / 1\right)$, pericardial effusion and positivity for anti-Sm antibody, which correspond to the diagnostic criteria for SLE formulated by the ACR (44). Therefore, the diagnosis of SLE was confirmed. According to the international SLE disease activity index scoring standard (49), the patient of the present study was identified as having a score of 14 points. Despite the definitive diagnosis of SLE, the patient had mild symptoms, clinical stability and no apparent organ damage. Considering the low activity and severity of the disease, as well as the potential of risk associated with treatment, SLE-associated treatment was not started at this point. In the present case, it was not clear whether hypothyroidism was a manifestation of SLE or a co-existing disease. The majority of patients present with SLE first and develop thyroid dysfunction at a later stage. Thyroid diseases may be the result of AAbs produced as a consequence of SLE. In the present case, hypothyroidism was the initial clinical manifestation and was apparently not linked to SLE in the course of the disease, and no similar manifestation was present in the patient's medical history. A possible reason for the initial occurrence of hypothyroidism and subsequent manifestation of SLE is that the two autoimmune diseases have a similar pathogenesis. Another potential reason for the unusual presentation in the present case is that the patient may have had low-severity SLE, which did not cause any specific clinical symptoms and was not detected. Hypothyroidism, caused by the destruction of thyroid follicular cells by autoimmune inflammation, may be the initial manifestation.

The association between pericardial effusion and hypothyroidism was first reported in the early 20th century (50), and has been reported successively since then (51-53). Pericardial effusion is a complication and indicator of the stage of SLE (54). Severe hypothyroidism and active SLE are known to 
Table II. Prevalence of hypothyroidism in patients with SLE in previously published studies.

\begin{tabular}{|c|c|c|c|c|c|c|}
\hline \multirow[b]{2}{*}{ Author, year } & \multicolumn{2}{|c|}{ Patients with SLE } & \multicolumn{2}{|c|}{ Controls } & \multirow[b]{2}{*}{ P-value } & \multirow[b]{2}{*}{ (Refs.) } \\
\hline & Cases (n) & Hypothyroidism (\%) & Cases (n) & Hypothyroidism (\%) & & \\
\hline Pyne and Isenberg, 2002 & 300 & 5.70 & - & - & NR & (7) \\
\hline Antonelli et al, 2010 & 201 & 5.90 & 402 & 0 & $<0.01$ & (8) \\
\hline Chan et al, 2001 & 69 & 4.30 & 0 & 0 & NR & (9) \\
\hline Park et al, 1995 & 63 & 9.50 & - & - & NR & (10) \\
\hline Boey et al, 1993 & 129 & 3.90 & - & - & NR & (11) \\
\hline Miller et al, 1987 & 332 & 6.60 & - & - & NR & (12) \\
\hline Vianna et al, 1991 & 100 & 3.00 & 100 & 0 & $<0.05$ & (13) \\
\hline Tsai et al, 1993 & 45 & 4.40 & - & - & $<0.05$ & (14) \\
\hline Mader et al, 2007 & 77 & 11.60 & 52 & 1.9 & 0.048 & $(15)$ \\
\hline Appenzeller et al, 2009 & 524 & 5.30 & 50 & 2 & $>0.05$ & (16) \\
\hline Kumar et al, 2012 & 100 & 14.00 & 100 & 8 & NR & (17) \\
\hline Stagnaro-Green et al, 2011 & 63 & 11.00 & 0 & 0 & $\mathrm{NR}$ & $(18)$ \\
\hline Gao et al, 2011 & 1,006 & 1.69 & - & - & $<0.01$ & (19) \\
\hline Ong and Choy, 2016 & 189 & 3.70 & - & - & NR & $(20)$ \\
\hline Watad et al, 2016 & 5,018 & 15.58 & 25,090 & 5.75 & $<0.001$ & $(21)$ \\
\hline Franco et al, 2015 & 376 & 12.00 & - & - & NR & (22) \\
\hline Song et al, 2014 & 220 & 57.80 & 160 & - & $<0.05$ & (23) \\
\hline Domingues et al, 2017 & 79 & 21.5 & 159 & 6.9 & 0.02 & (24) \\
\hline
\end{tabular}

SLE, systemic lupus erythematosus; NR, not reported.

lead to the development of pericardial effusion. In the present case, pericardial effusion may have been caused by hypothyroidism alone or in combination with SLE. Hypothyroidism was the first clinical manifestation in the current case and the patient had normal blood sedimentation, no history of tuberculosis contact, normal tumor markers and multiple negative examinations of pericardial effusion-shedding cells. Therefore, tuberculous pericardial effusion and neoplastic pericardial effusion were excluded according to the differential diagnosis $(55,56)$ combined with the patient's symptoms. Due to technical limitations, anti-nuclear antibody testing of pericardial effusion was not possible; however, this indicator may have been helpful in determining the etiology.

The clinical symptoms of hypothyroidism myopathy, muscle weakness and elevation of serum enzymes are not specific and are similar to polymyositis, defined as hypothyroidism polymyositis syndrome (57). The difference between the two diseases is mainly based on muscle biopsies indicating normal or slight non-specific changes in hypothyroidism polymyositis syndrome. The major feature of polymyositis is lymphocyte infiltration, with the characteristic immunopathology of $\mathrm{CD} 8^{+} \mathrm{T} / \mathrm{major}$ histocompatibility complex-I injury (58). Combined with the results of muscle biopsy in the present case, myositis was excluded. Prolactin was increased in the patient of the present study, although there were no symptoms of lactation or menoxenia. However, pituitary MRI revealed the presence of a pituitary microadenoma. At present, MRI is the preferred imaging method for pituitary lesions. Pituitary tumors and hypothyroidism-induced pituitary hyperplasia have certain characteristic manifestations, but both may present on MRI as pituitary enlargement, spherical or nodular. Primary hypothyroidism may also lead to pituitary feedback neoplasia, which is challenging to identify, and in the present case, it may not be excluded that the increase of pituitary hormone secretion was due to hypothyroidism or a pituitary tumor. Therefore, no specific treatment was provided and the patient was instructed to present for regular review to observe whether prolactin normalized under the control of primary hypothyroidism (59). After 3 months of thyroid hormone replacement therapy, the patient was followed up at the outpatient clinic and pituitary MRI revealed that the size of pituitary microadenoma decreased from $6.4 \mathrm{~mm}$ at the first presentation to $1.8 \mathrm{~mm}$, and prolactin levels were significantly decreased from 1,280.90 to $794.9 \mathrm{mIU} / \mathrm{l}$.

In conclusion, the prevalence of hypothyroidism in SLE is high, whereas studies regarding hypothyroidism as the first or the only symptom of SLE are rare. Although the clinical manifestations of SLE are diverse, the current case lacked characteristic manifestations of SLE and hypothyroidism was the major manifestation. Therefore, attention should be paid to screening for SLE while diagnosing hypothyroidism and the importance of thyroid dysfunction should also be recognized in the treatment of SLE. This may help identify diseases at an earlier stage.

The limitation of the present study is its retrospection; it was only possible to review the literature and analyze previous studies to provide relevant information.

\section{Acknowledgements}

Not applicable. 


\section{Funding}

No funding was received.

\section{Availability of data and materials}

The datasets used and analyzed during the present study are available from the corresponding author on reasonable request.

\section{Authors' contributions}

RL and QW analyzed and interpreted the patient data regarding the SLE and hypothyroidism diseases, and revised the manuscript. BFX and XJZ contributed to the conception and design of the study and performed the data analyses and wrote the manuscript. ZWL and YYG performed the analysis with constructive discussions, carried out the study and collected important background information and reviewed the references. All authors read and approved the final manuscript.

\section{Ethics approval and consent to participate}

Ethics committee of China-Japan Union Hospital of Jilin University (approval no. 2020032602).

\section{Patient consent for publication}

The patient provided written informed consent for the publication of any associated data and accompanying images.

\section{Competing interests}

The authors declare that they have no competing interests.

\section{References}

1. Aringer $M$ and Schneider M: Systemic lupus erythematosus Dtsch Med Wochenschr 141: 537-543, 2016 (In German).

2. Ekinci RMK, Balcı S, Celik G, Dogruel D, Altıntas DU and Yilmaz M: Symptomatic multifocal avascular necrosis in an adolescent with neuropsychiatric systemic lupus erythematosus. Reumatologia 57: 182-187, 2019.

3. Bharath G, Kumar P, Makkar N, Singla P, Soneja M, Biswas A and Wig N: Mortality in systemic lupus erythematosus at a teaching hospital in India: A 5-year retrospective study. J Family Med Prim Care 8: 2511-2515, 2019.

4. Blich M, Rozin A and Edoute Y: Systemic lupus erythematosus and thyroid disease. Isr Med Assoc J 6: 218-220, 2004.

5. Luo W, Mao P, Zhang L and Yang Z: Association between systemic lupus erythematosus and thyroid dysfunction: A meta-analysis. Lupus 27: 2120-2128, 2018.

6. Chen X: The significance of rivalta experiment in the diagnosis of ascites. Chinese Community Doctors 15: 253, 2013 (In Chinese).

7. Pyne D and Isenberg DA: Autoimmune thyroid disease in systemic lupus erythematosus. Ann Rheum Dis 61: 70-72, 2002.

8. Antonelli A, Fallahi P, Mosca M, Ferrari SM, Ruffilli I, Corti A, Panicucci E, Neri R and Bombardieri S: Prevalence of thyroid dysfunctions in systemic lupus erythematosus. Metabolism 59: 896-900, 2010

9. Chan AT, Al-Saffar Z and Bucknall RC: Thyroid disease in systemic lupus erythematosus and rheumatoid arthritis. Rheumatology (Oxford) 40: 353-354, 2001.

10. Park DJ, Cho CS, Lee SH, Park SH and Kim HY: Thyroid disorders in Korean patients with systemic lupus erythematosus. Scand J Rheumatol 24: 13-17, 1995.

11. Boey ML, Fong PH, Lee JS, Ng WY and Thai AC: Autoimmune thyroid disorders in SLE in Singapore. Lupus 2: 51-54, 1993.
12. Miller FW, Moore GF, Weintraub BD and Steinberg AD: Prevalence of thyroid disease and abnormal thyroid function test results in patients with systemic lupus erythematosus. Arthritis Rheum 30: 1124-1131, 1987.

13. Vianna JL, Haga HJ, Asherson RA, Swana G and Hughes GR: A prospective evaluation of antithyroid antibody prevalence in 100 patients with systemic lupus erythematosus. J Rheumatol 18: 1193-1195, 1991.

14. Tsai RT, Chang TC, Wang CR, Chuang CY and Chen CY: Thyroid disorders in Chinese patients with systemic lupus erythematosus. Rheumatol Int 13: 9-13, 1993.

15. Mader R, Mishail S, Adawi M, Lavi I and Luboshitzky R: Thyroid dysfunction in patients with systemic lupus erythematosus (SLE): Relation to disease activity. Clin Rheumatol 26: 1891-1894, 2007.

16. Appenzeller S, Pallone AT, Natalin RA and Costallat LT: Prevalence of thyroid dysfunction in systemic lupus erythematosus. J Clin Rheumato 15: 117-119, 2009.

17. Kumar K, Kole AK, Karmakar PS and Ghosh A: The spectrum of thyroid disorders in systemic lupus erythematosus. Rheumatol Int 32: 73-78, 2012.

18. Stagnaro-Green A, Akhter E, Yim C, Davies TF, Magder L and Petri M: Thyroid disease in pregnant women with systemic lupus erythematosus: Increased preterm delivery. Lupus 20: 690-699, 2011.

19. Gao H, Li C, Mu R, Guo YQ, Liu T, Chen S, Su Y and Li ZG: Subclinical hypothyroidism and its association with lupus nephritis: A case control study in a large cohort of Chinese systemic lupus erythematosus patients. Lupus 20: 1035-1041, 2011.

20. Ong SG and Choy $\mathrm{CH}$ : Autoimmune thyroid disease in a cohort of Malaysian SLE patients: Frequency, clinical and immunological associations. Lupus 25: 67-74, 2016.

21. Watad A, Mahroum N, Whitby A, Gertel S, Comaneshter D, Cohen AD and Amital H: Hypothyroidism among SLE patients: Case-control study. Autoimmun Rev 15: 484-486, 2016.

22. Franco JS, Amaya-Amaya J, Molano-González N, Caro-Moreno J, Rodríguez-Jiménez M, Acosta-Ampudia Y, Mantilla RD, Rojas-Villarraga A and Anaya JM: Autoimmune thyroid disease in Colombian patients with systemic lupus erythematosus. Clin Endocrinol (Oxf) 83: 943-950, 2015.

23. Song Q, Mao YJ, Li J and Guo XH: Correlation between systemic lupus erythematosus and autoimmune thyroid diseases. Chin J General Practice 13: 742-744, 2014 (In Chinese).

24. Domingues SL, Gonçalves FT, Jorge MLMP, Limongi JE, Ranza R and Jorge PT: High prevalence of hypothyroidism in systemic lupus erythematosus patients without an increase in circulating anti-thyroid antibodies. Endocr Pract 23:1304-1310, 2017.

25. Rahman A and Isenberg DA: Systemic lupus erythematosus. N Engl J Med 358: 929-939, 2008.

26. Pan Q, Chen X, Liao S, Chen X, Zhao C, Xu YZ and Liu HF: Updated advances of linking psychosocial factors and sex hormones with systemic lupus erythematosus susceptibility and development. Peer J 7: e7179, 2019.

27. Hijmans W, Doniach D, Roitt IM and Holborow EJ: Serological overlap between lupus erythematosus, rheumatoid arthritis, and thyroid auto-immune disease. Br Med J 2: 909-914, 1961.

28. Rivas-Larrauri F and Yamazaki-Nakashimada MA: Systemic lupus erythematosus: Is it one disease? Reumatol Clin 12: 274-281, 2016 (In Spanish).

29. Liu YC, Lin WY, Tsai MC and Fu LS: Systemic lupus erythematosus and thyroid disease-experience in a single medical center in Taiwan. J Microbiol Immunol Infect 52: 480-486, 2019.

30. Lisnevskaia L, Murphy G and Isenberg D: Systemic lupus erythematosus. Lancet 384: 1878-1888, 2014.

31. Posselt RT, Coelho VN and Skare TL: Hashimoto thyroiditis, anti-thyroid antibodies and systemic lupus erythematosus. Int J Rheum Dis 21: 186-193, 2018.

32. Green LM, LaBue M, Lazarus JP and Colburn KK: Characterization of autoimmune thyroiditis in MRL-lpr/lpr mice. Lupus 4: 187-196, 1995.

33. Apostolidis SA, Lieberman LA, Kis-Toth K, Crispín JC and Tsokos GC: The dysregulation of cytokine networks in systemic lupus erythematosus. J Interferon Cytokine Res 31: 769-779, 2011.

34. Zlotnik A and Yoshie O: Chemokines: A new classification system and their role in immunity. Immunity 12: 121-127, 2000.

35. Ahmadpoor P, Dalili N and Rostami M: An update on pathogenesis of systemic lupus erythematosus. Iran J Kidney Dis 8: 171-184, 2014. 
36. Tsokos GC: Systemic lupus erythematosus. N Engl J Med 365 2110-2121, 2011.

37. Kawashima A, Tanigawa K, Akama T, Yoshihara A, Ishii N and Suzuki K: Innate immune activation and thyroid autoimmunity. J Clin Endocrinol Metab 96: 3661-3671, 2011.

38. Scharer CD, Blalock EL, Mi T, Barwick BG, Jenks SA, Deguchi T, Cashman KS, Neary BE, Patterson DG, Hicks SL, et al: Epigenetic programming underpins B cell dysfunction in human SLE. Nat Immunol 20: 1071-1082, 2019.

39. Ferrari SM, Elia G, Virili C, Centanni M, Antonelli A and Fallahi P: Systemic lupus erythematosus and thyroid autoimmunity. Front Endocrinol (Lausanne) 8: 138, 2017.

40. Wu H, Cantor RM, Graham DS, Lingren CM, Farwell L, Jager PL, Bottini N, Grossman JM, Wallace DJ, Hahn BH, et al: Association analysis of the R620W polymorphism of protein tyrosine phosphatase PTPN22 in systemic lupus erythematosus families: Increased $\mathrm{T}$ allele frequency in systemic lupus erythematosus patients with autoimmune thyroid disease. Arthritis Rheum 52: 2396-2402, 2005.

41. Antonelli A, Ferrari SM, Corrado A, Di Domenicantonio A and Fallahi P: Autoimmune thyroid disorders. Autoimmun Rev 14: 174-180, 2015.

42. Biondi B and Cooper DS: Thyroid hormone therapy for hypothyroidism. Endocrine 66: 18-26, 2019.

43. Arbuckle MR, McClain MT, Rubertone MV, Scofield RH, Dennis GJ, James JA and Harley JB: Development of autoantibodies before the clinical onset of systemic lupus erythematosus. N Engl J Med 349: 1526-1533, 2003.

44. Aringer M, Costenbader K, Daikh D, Brinks R, Mosca M, Ramsey-Goldman R, Smolen JS, Wofsy D, Boumpas DT, Kamen DL, et al: 2019 European league against Rheumatism/American College of rheumatology classification criteria for systemic lupus erythematosus. Arthritis Rheumatol 71: 1400-1412, 2019.

45. Petri M, Orbai AM, Alarcón GS, Gordon C, Merrill JT, Fortin PR, Bruce IN, Isenberg D, Wallace DJ, Nived O, et al: Derivation and validation of the systemic lupus international collaborating clinics classification criteria for systemic lupus erythematosus. Arthritis Rheum 64: 2677-2686, 2012.

46. Budde P, Zucht HD, Vordenbäumen S, Goehler H, Fischer-Betz R, Gamer M, Marquart K, Rengers P, Richter J, Lueking A, et al: Multiparametric detection of autoantibodies in systemic lupus erythematosus. Lupus 25: 812-822, 2016.

47. Tan EM: Autoantibodies, autoimmune disease, and the birth of immune diagnostics. J Clin Invest 122: 3835-3836, 2012.
48. Zeng YK and Wu J: Diagnostic value of combined detection of anti-nuclear antibody, anti-nuclear antibody spectrum and anti-double-stranded DNA antibody in systemic lupus erythematosus. Med Clin Res: 2081-2083, 2014.

49. Zai Y, Zhong NS and Xie Y: Internal medicine [M]. Version 7. Beijing: People's medical publishing house 86, 2008.

50. Gordon AH: Some clinical aspects of hypothyroidism. Can Med Assoc J 20: 7-10, 1929.

51. Wang JL, Hsieh MJ, Lee CH, Chen CC, Hsieh IC, Lin JD, Lin FC and Hung KC: Hypothyroid cardiac tamponade: Clinical features, electrocardiography, pericardial fluid and management. Am J Med Sci 340: 276-281, 2010

52. Martinez-Soto T, Deal C, Stephure D, Trussell R, Boutin C, Djemli A and Ho J: Pericardial effusion in severe hypothyroidism in children. J Pediatr Endocrinol Metab 23: 1165-1168, 2010.

53. Agarwal A, Chowdhury N, Mathur A, Sharma S and Agarwal A: Pericardial effusion with cardiac tamponade as a form of presentation of primary hypothyroidism. J Assoc Physicians India 64: 98-100, 2016.

54. Mohamed AAA, Hammam N, El Zohri MH and Gheita TA: Cardiac manifestations in systemic lupus erythematosus: Clinical correlates of subclinical echocardiographic features. Biomed Res Int 2019: e2437105, 2019.

55. Abdallah R and Atar S: Etiology and characteristics of large symptomatic pericardial effusion in a community hospital in the contemporary era. QJM 107: 363-368, 2014.

56. Ozturk E, Tanidir IC, Saygi M, Ergul Y, Guzeltas A and Odemis E: Evaluation of non-surgical causes of cardiac tamponade in children at a cardiac surgery center. Pediatr Int 56: 13-18, 2014.

57. Madariaga MG: Polymyositis-like syndrome in hypothyroidism: Review of cases reported over the past twenty-five years. Thyroid 12: 331-336, 2002.

58. Scott KR, Simmons Z and Boyer PJ: Hypothyroid myopathy with a strikingly elevated serum creatine kinase level. Muscle Nerve 26: 141-144, 2002.

59. Nachawi N and Bodnar TW: Pituitary 'pseudotumor': An under-recognised complication of undertreated primary hypothyroidism. BMJ Case Rep 2018: bcr-2018-225472, 2018.

This work is licensed under a Creative Commons Attribution-NonCommercial-NoDerivatives 4.0 International (CC BY-NC-ND 4.0) License. 